\title{
Value of multimodal imaging in recurrent pericarditis - clinical burden of hemodynamic and inflammation imaging
}

\author{
(DSandra Jakšić \\ Jurinjak ${ }^{*}$, \\ (i) Vlatka Rešković \\ Lukšić', \\ (DDiana Kovač ${ }^{2}$, \\ DBlanka Glavaš Konja', \\ (DMarija Brestovac', \\ (D)Marina Prpićc', \\ (D)Zvonimir Ostojić', \\ (D) Joško Bulum', \\ (D) Martina Lovrić \\ Benčić'

\section{(D)Jadranka Šeparović Hanževački ${ }^{1}$}

'University of Zagreb School of Medicine, University Hospital Centre Zagreb, Zagreb, Croatia

2University of Zagreb School of Medicine, Zagreb, Croatia
KEYWORDS: cardiac imaging, recurrent pericarditis, inflammation.
CITATION: Cardiol Croat. 2021;16(5-6):196-7. | https://doi.org/10.15836/ccar2021.196

*ADDRESS FOR CORRESPONDENCE: Sandra Jakšić Jurinjak, Klinički bolnički centar Zagreb, Kišpatićeva 12, HR10000 Zagreb, Croatia. / Phone: +385-1-2388-888 / E-mail: sjaksicj@gmail.com

ORCID:Sandra Jakšić Jurinjak, https://orcid.org/0000-0002-7349-6137• Vlatka Rešković Lukšić, https://orcid.org/0000-0002-4721-3236 Diana Kovač, https://orcid.org/0000-0002-5098-1594 • Blanka Glavaš Konja, https://orcid.org/0000-0003-1134-4856 Marija Brestovac, https://orcid.org/0000-0003-1542-2890 • Marina Prpić, https://orcid.org/0000-0002-0635-3806 Zvonimir Ostojić, https://orcid.org/0000-0003-1762-9270 • Joško Bulum, https://orcid.org/0000-0002-1482-6503 Martina Lovrić Benčić, https://orcid.org/0000-0001-8446-6120 • Jadranka Šeparović Hanževački, https://orcid.org/0000-0002-3437-6407

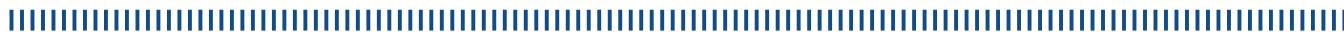

Introduction: Recurrent pericarditis can occur in up to $30 \%$ of patients after acute episode of pericarditis and is associated with significantly impaired quality of life and morbidity ${ }^{1}$. High rate of recurrence remains despite treatment as nonsteroidal anti-inflammatory drugs (NSAIDs), colchicine, steroids or other immunosuppressants ${ }^{1}$. If medical therapy fails, in case of symptomatic constrictive hemodynamics, surgical approach-pericardiectomy is indicated. Therefore, imaging modalities have to distinguish between hemodynamic assessment, where echocardiography is first line imaging modality, and inflammation where other cardiac imaging modalities complement echocardiographic findings ${ }^{2}$. Case report: We present series of two cases, first of recurrent pericarditis in patient with postpericardiotomy syndrome and second recurrent pericarditis which lead to constrictive pericarditis resolved by pericardiectomy. First case is 60 -year female who had aortic valve replacement due to severe aortic stenosis three weeks prior development of first symptoms, comprised of severe chest pain, fever with elevated markers of infection, and pleural effusion. Echocardiography revealed normal function of artificial aortic valve, normal ejection fraction of left and right ventricle and pericardial effusion, mainly inferoposterolateral and in front of right ventricle with septal bounce and hemodynamic signs of elastic constriction. PET CT confirmed inflammation only in pericardium and pleura (Figure 1)
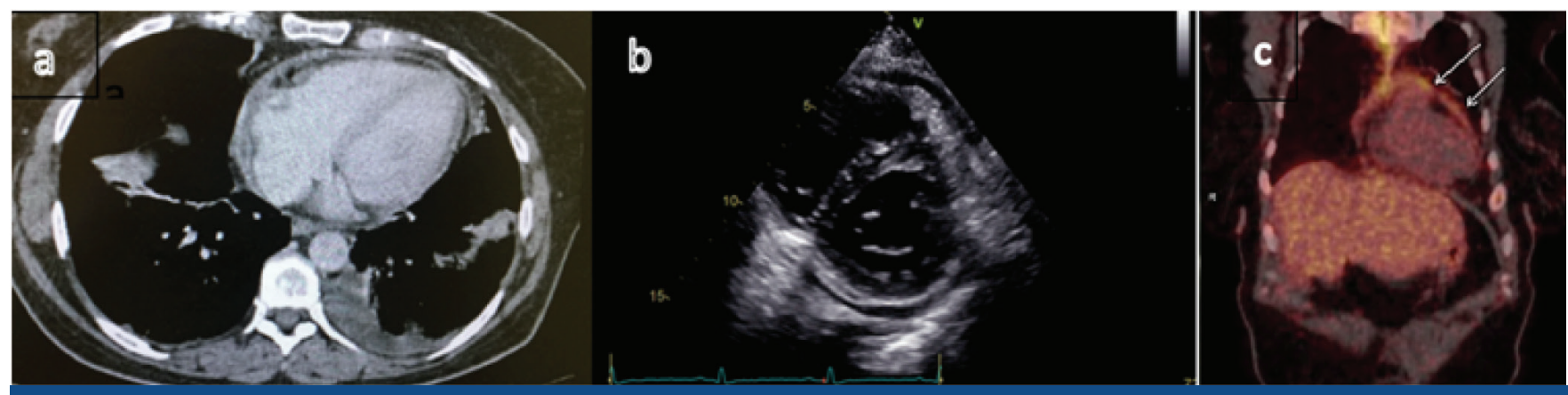

FIGURE 1. A) Chest CT showing pericardial and pleural effusion. B) echocardiography showing pericardial effusion. C) PET CT identifying inflammation of the pericardium.

RECEIVED:

March 28, 2021

ACCEPTED:

April 2, 2021

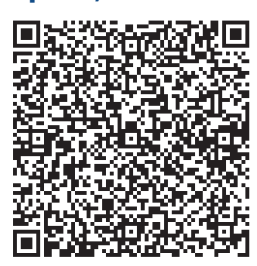

Regression followed due to NSAIDs, colchicine, steroids treatment. She had signs of recurrence within next six month, but less severe inflammation. Second case is 45-year male who was admitted to our institution due to right heart failure and atrial undulation. Echocardiography revealed septal bounce with respiratory dependent septal shift to the right as result of interventricular interdependence due to severe calcification of pericardium mainly in front of right ventricle and pericardial effusion inferolaterally. CT revealed massive calcification of the pericardium and no active inflammation in patient with right heart failure leading us to indicate surgical treatment pericardiectomy (Figure 2). Patient is recovering after surgery and was discharged in good condition.

$\square$ Cardiologia Croatica 2021;16(5-6):196.
CroEcho2021

$11^{\text {th }}$ Croatian Biennal Echocardiography Congress with International Participation / 11. hrvatski dvogodišnji ehokardiografski kongres s međunarodnim sudjelovanjem Virtual Congress, May 6-8, 2021 

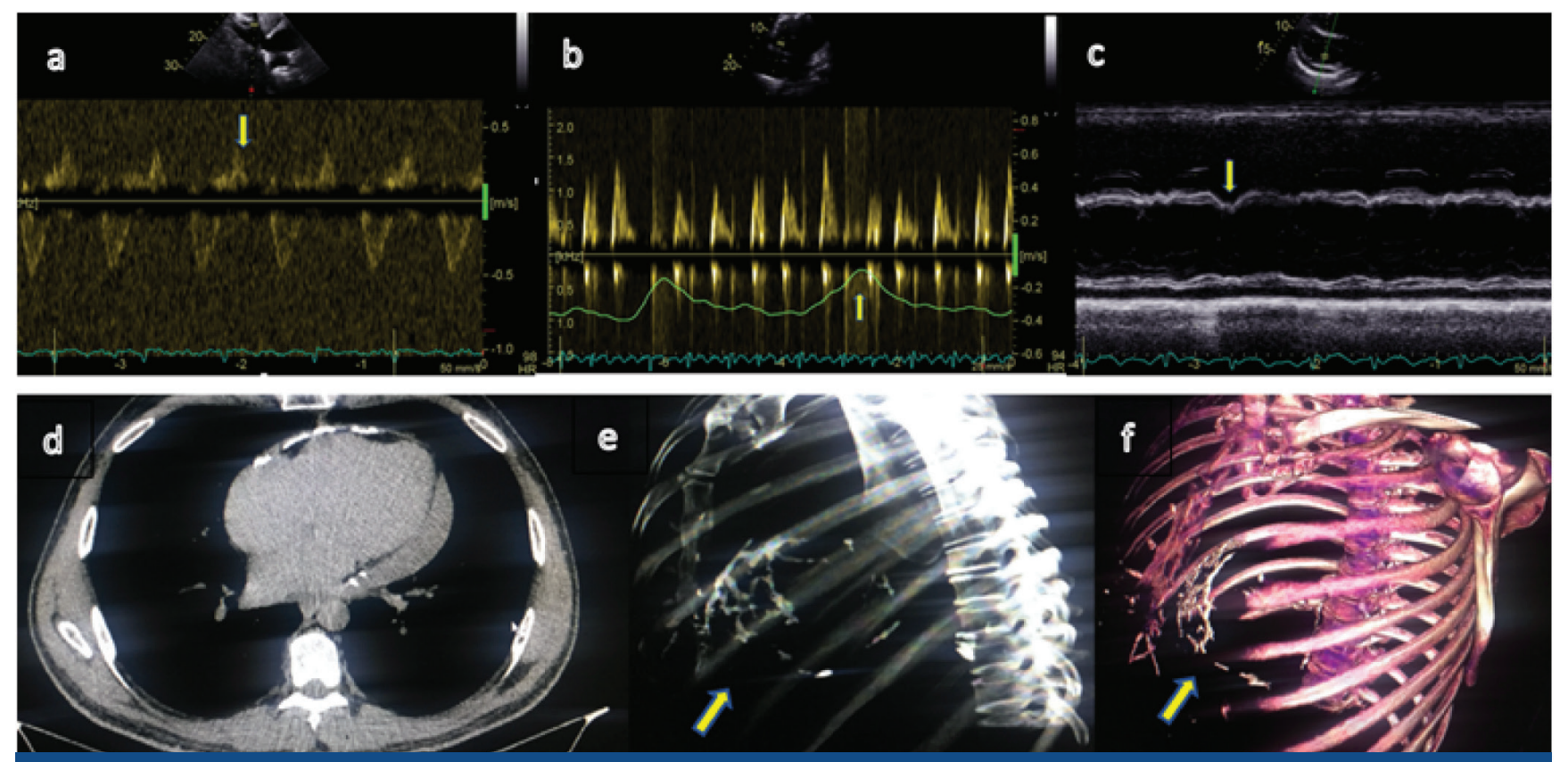

FIGURE 2. A) Hepatic flow reversal with IVC plethora. B) Hemodynamic information bet seen by echo C) Diastolic septal bounce best seen on M mode as septal notch in early diastole. D, E, F) CT showing pericardial calcification.

Conclusion: Multidisciplinary approach to pericardial disease and multimodality imaging of pericardial pathology is paramount, as diagnosis and treatment often include multiple subspecialties. Echocardiography is still superior imaging modality when hemodynamic is the question but is best complemented with imaging modalities indicating inflammation.

LITERATURE IIIIIIIIIIIIIIIIIIIIIIIIIIIIIIIIIIIIIIIIIIIIIIIIIIIIIIIIIIIIIIIIIIIIIIIIIIIIIIIIIIIIIIIIIIIIIIIIIIIIIIIIIIIIIIIIIIIIIIIIIIIIIIIIIIIIII

1. Chiabrando JG, Bonaventura A, Vecchié A, Wohlford GF, Mauro AG, Jordan JH, et al. Management of Acute and Recurrent Pericarditis: JACC State-of-the-Art Review. J Am Coll Cardiol. 2020 Jan 7;75(1):76-92. https://doi.org/10.1016/j.jacc.2019.11.021

2. Klein AL, Cremer PC. Ephemeral Effusive Constrictive Pathophysiology. JACC Cardiovasc Imaging. 2018 Apr;11(4):542-545. https://doi.org/10.1016/j.jcmg.2017.10.028 